\title{
Corpo e Cultura \\ No contexto da sociedade brasileira
}

\author{
Body and culture \\ 0 ccording to the brazilian society
}

JOSÉ TRASFERETTI

Professor da PUC-Campinas e Dr. em Filosofia e Teologia, Presidente da Sociedade

Brasileira de Teologia Moral.

\begin{abstract}
Resumo
Trata-se de estudar as relações entre corpo, cultura e sociedade descortinando a temática do corpo como norteadora da ação do homem no mundo. A sociedade caracterizada pelos condicionamentos capitalistas aplica um corporicídio transformando o corpo em fonte de exploração do mercado, da mídia, da estética, da saúde. As produções simbólicas e culturais geradas neste contexto carregam um sentimento de alienação e destruição do corpo enquanto relação de alteridade e comunicação profunda.

Palavras-chave: corpo, sociedade, cultura, ética.
\end{abstract}

Introdução

Nosso século apagou a linha divisória do "corpo" e do "espirito", vendo a vida humana inteiramente como espiritual e como corporal, sempre apoiada no corpo, sempre interessada, aténos seus modos mais carnais, nas relações entre as pessoas. Para muitos pensadores do fim do século XIX, o corpo era um pedaço de matéria, um feixe de mecanismos. $O$ século $X X$, restaurou e aprofundou a noção de carne, ou seja, do corpo animado. (MERLEAU-PONTY, 1960, p. 287).

Trata-se de compreender o corpo como fonte primeira de ação e comunicação moral no interior da sociedade. Toda ação que realizamos e toda relação que construímos coloca sempre em xeque-mate nossa corporeidade. O corpo é a instância suprema do existir no mundo e lugar de toda moralidade enquanto alteridade. As variantes do corpo enquanto saúde, enfermidade, sexualidade, ética, pessoa, valores, objeto de desejo serão analisados no contexto de uma abordagem social. $\mathrm{Na}$ cultura pós-moderna o corpo aparece sempre como um produto cultural vivendo a ambigüidade do aniquilamento e da divinização.

Corpo e Sociedade

Antropólogos, sociólogos, filósofos, psicólogos e tantos outros profissionais têm se debruçado sobre a questão do corpo. Os filósofos, particularmente, têm procurado estudar o corpo mostrando a configuração de todo ser humano como um corpo que se comunica e se faz presença no mundo. O ser humano possui e ao mesmo tempo é um corpo. Um corpo que se comunica, que se expressa, que ama. Nesse sentido, o corpo está em toda a parte. Ele acompanha nossa existência como seres carnais 
(alimentação, sexualidade, saúde), ele faz parte das nossas representações lingüísticas (estética, ética, direito). A reflexão sobre o corpo abrange uma vasta área do saber cujo conteúdo se expressa através das mais variadas linguagens que caracterizam sua expressão e ao mesmo tempo revelam seu comportamento ético a partir das opções e situações de escolha.

Cada pessoa humana se relaciona com o seu corpo e com o corpo dos outros. A pessoa humana se reconhece a si mesma como um ser que se constrói fazendo-se relação, tomando decisões, que arbitrariamente ou não condicionam o seu existir enquanto um feixe de sentido moral no conjunto da vida; pois o corpo é um objeto de representações, de manipulações, de cuidados e de construções culturais próprias de cada contexto sóciopolítico. A cultura constrói corpos segundo suas regras de mercado e de religião e os transforma em ícones de saúde ou mesmo de retórica moral.

Assim, cada gesto corporal enquanto expressão de vida, indica o sentido da minha própria intencionalidade: intencionalidade em relação a mim mesmo e ao corpo do outro, que passa a se constituir num paradoxo de minha própria existência, que me faz crescer. O outro se apresenta com sua relevância no combate cotidiano, cujas vidas se confrontam no mistério do agir moral que transforma tudo em atitudes, desejos, emoções e sentimentos. $\mathrm{O}$ corpo representa a fala, a natureza das emoções a intensidade do conhecimento, o lugar da moralidade. Movimentamos nosso corpo em direção de propostas reais, sensações transitórias que ficaram inscritas no espaço e no tempo. Somos parte de um todo, circunflexo existir que tudo permeia com sua magnitude existencial.

O vocabulário cotidiano do mundo contemporâneo fez do corpo um dos assuntos mais divulgados e ao mesmo tempo uma das realidades mais controversas. Objeto de consumo no mundo capitalista, o corpo é venerado e ao mesmo tempo negado, numa escorregadia ambigüidade traçada a partir do exterior. Ás vezes aceito (quando está adequado a padronização do consumo), outras negado (quando sua construção externa não obedece as determinações do mercado). Deste modo, o corpo não pertence à pessoa, mas às regras e orientações, artifícios e disfarces do mundo social. As pessoas procuram ajustar seus corpos (aparência física e conduta) aos cânones da moral oficial numa clara tentativa de se auto-valorizar a partir das regras sociais impostas.

As regras sociais determinam a conduta também no campo da saúde. O discurso médico, no mundo capitalista, tem feito da saúde o bem último a conquistar. Saúde é importante, mas é preciso ter a clareza exata da fragilidade do corpo, bem como, da sua finitude enquanto materialidade. Corpo também está associado a enfermidade, desvios de conduta, depressão moral. Numa sociedade que valoriza em demasia o corpo sadio, não se permite nenhuma fraqueza. Todos buscam o "corpo sarado", sem dores e malefícios. Querem estar sempre esbeltos, magros, determinados. Vemos proliferar abundantemente as academias, casas de massagens, produtos dietéticos, lipoaspirações, cirurgias plásticas, cremes e cosméticos. Mas o corpo é frágil, pequeno e, fugaz. O mundo capitalista atual é produto de uma contradição irreconciliável; de um lado a busca da saúde e de outro o stress, destruição de matas e florestas, lucro 
a qualquer preço. Por mais que queiramos não conseguimos comprar a beleza, a alegria, a paz espiritual. Em sua materialidade consubstancial o corpo é finito e não existem cremes, cirurgias, remédios que possam impedir o tempo de realizar o seu trabalho. O corpo envelhece e morre. O tempo é irreversivelmente cruel.

O mundo dos desejos e sensações nos coloca diante da sexualidade enquanto forma de se dar no mundo das paixões e sentimentos. Somos uma alma viva, que busca a satisfação e o gozo. Mas como se dá este processo nesta sociedade onde tudo é produzido artificialmente. Nunca se vendeu tantas ilusões no campo da sexualidade. O mercado é prolixo, os produtos à disposição mexem com a mente e o coração de bilhões de seres humanos. A sexualidade é uma energia vital que desperta sentimentos positivos, que constrói relações salutares, mas ao mesmo tempo nunca se viu tantas pessoas doentes e os consultórios médicos nunca estiveram tão cheios. $\mathrm{O}$ amor e o desejo sexual sempre se constituíram numa abertura ao outro, numa relação profunda que educa pessoas e as devolve o equilíbrio em seu existir. Somos um corpo sexuado, mas, é preciso buscar o equilíbrio numa sociedade que procura fazer do corpo e sua intimidade (a sexualidade) um produto de consumo. Empresários do sexo ganham dinheiro vendendo corpos humanos, revistas, sites e produtos eróticos. A mídia que está à serviço do capitalismo tem investido fortemente no corpo enquanto produto sexual (alienado) capaz de garantir altos lucros aos investidores. $\mathrm{O}$ que fazer?

A questão do corpo na sociedade capitalista está profundamente marcada pela cultura pós-moderna que valoriza o corpo enquanto individualidade, capacidade de decisão, autonomia, liberdade, mas ao mesmo tempo produto cultural. Para resgatar a dignidade do corpo é preciso retomar o conceito de possessão ontológica e pertença, pois ambos colocam o corpo em sua possibilidade ética de existir num mundo de direitos e deveres. Parodiamos Marzano-Parizoli para afirmar que "o corpo pertence, efetivamente, a pessoa, pois, para cada indivíduo, seu corpo é exatamente seu corpo: o corpo não é um simples objeto do mundo, mas é o objeto que cada um, ao mesmo tempo, tem e é; ele é uma coisa, uma coisa sui generis; ele é aquilo de que podemos dispor, mas cuja disposição jamais é absoluta". (PARISOLI, 2004, p. 22)

Quando nos propomos a realizar uma reflexão mais aprofundada acerca do corpo, sobretudo sob a ótica da filosofia, cabe a nós uma ponderação inicial acerca das forças opostas da valorização e negação do corpo humano. É preciso buscar uma compreensão mais apurada acerca de como o corpo humano se apresenta enquanto realidade material no mundo de hoje. Muitas são as facetas que se nos apresentam quando pretendemos conhecer e analisar a questão do corpo, no entanto, no presente trabalho nossa intenção é lançar um olhar sobre a ambigüidade do corpo nas suas mais variadas formas de negação e afirmação.

Partindo do pressuposto de que filosofar, entre outras coisas, é refletir o sentido da prática realizada, podemos promover uma reflexão mais apurada sobre a questão do corpo na pós-modernidade. Partindo da realidade concreta, a fim de não dar espaço à alienação, podemos nos questionar sobre as dificuldades de se pensar no problema do corpo 
numa sociedade que considera tudo e todos como meros objetos. A constatação de que a sociedade pósmoderna tem como dogma fundamental de sua doutrina a "coisificação" do ser humano nos leva a mensurar o grau de dificuldade em que o problema do resgate da corporeidade está imerso.

Numa rápida olhadela pelos outdoors, cartazes, revistas, jornais, sites, propagandas e letras de música, logo perceberemos o quanto o corpo está presente em tudo isso, o que é um indício de que a sociedade hodierna lhe atribui um significado específico que é fruto de uma manipulação, como um sinal ou um código produzido pela política de industrialização/urbanização que visa nada mais nada menos que ampliar o mercado consumidor. Esse controle do mercado consumidor tenta (e quase sempre consegue) manipular verbas publicitárias do Estado, acrescidas de outras verbas provenientes de grupos ou empresas que se beneficiam dessa "objetificação" do corpo, promovendo um alinhamento da indústria cultural brasileira ao modelo capitalista internacional.

Para ilustrar o quanto a indústria cultural brasileira tem se alinhado a esse modelo capitalista, que nada tem de seu, poderíamos nos reportar ao tão difuso exemplo das revistas femininas, divulgadas amplamente $\mathrm{e}$ que atraem a atenção das mulheres de classe média alta e baixa, propondo indistintamente parâmetros de vida e beleza que são próprios das classes superiores. Devido a isso, os ideais que são propostos nessas revistas, se apresentam como modelos a serem seguidos. Mesmo que esses parâmetros jamais cheguem à perfeita efetivação, ainda assim, acabam contribuindo para a promoção de um esforço desmedido que pretende alcançar ao menos em parte o que é proposto por eles; com isso, o consumo (de roupas, perfumes, etc.) aumenta em detrimento de outras necessidades por vezes até mais urgentes.

A questão da apresentação estética do corpo, também é algo preocupante. No tempo do verão, não raro nos deparamos com homens e mulheres que procuram se adequar o máximo possível aos padrões de beleza difundidos pela mídia, a fim de que ao se dirigirem à praia "não passem vergonha". Desse modo, todo o esforço para manter ou desenvolver um corpo "malhado", uma pele firme, pernas torneadas, quadris bem ordenados, bustos belos, e muitos outros elementos, tudo ainda é pouco. Aos indivíduos que a natureza não ofereceu esses "preciosos presentes", cabe-lhes tentar conquistá-los através de remédios para emagrecer (oferecidos à revelia em programas de televisão), de exercícios físicos acompanhados por profissionais em academias especializadas, em locais que oferecem bronzeamento artificial aos que possuem uma pele demasiadamente branca, etc. Enfim, são essas algumas das regras de conduta propostas aos homens e mulheres contemporâneos, que diariamente são interpelados pelo modelo capitalista internacional que movimenta seus lucros e dita seus preceitos através de sua potente porta-voz: a indústria cultural.

No fundo, podemos analisar que muitos desejam ou pretendem tornar o corpo conforme os ideais, mitos, exemplos da beleza das classes superiores, "cânones de uma beleza que são talvez apenas expressão simbólica do tipo de relação que os membros dessas classes mantêm em seu corpo, do tipo de uso que fazem deste, da função que lhes atribuem (BOLTANSKI, 1979, p. 183). 
O desejo de moldar o corpo conforme o padrão de beleza extraído das classes superiores denota a vergonha que outras classes têm de seus corpos, porém, por detrás disso há ainda um problema maior: a vergonha de classes, isto é, a vergonha de não pertencer a um grupo social mais elevado; e embutido nessa vergonha vem o desejo de pertencer a um grupo social que não é o seu, mas que apresenta ideais que atraem sua atenção e motiva seus esforços de rejeição ao seu próprio grupo, e sujeição ao grupo desejado (muitas vezes como um fim em si mesmo). Essa espinhosa questão tem como pano de fundo a posse de certos caracteres corporais que confiram certo status ao indivíduo, tanto que a posse de um corpo "perfeito" considerados os padrões de beleza que a sociedade atual impõe equivale ou até mesmo supera, em alguns casos, a posse de outros bens que poderiam conferir ou aumentar o status de uma pessoa. O status haurido do cultivo de alguns caracteres básicos como: cor, textura da pele, volume, forma e ainda outros elementos, possui um significado simbólico que ultrapassa a qualquer outro, pois é algo que está na pessoa e que é a pessoa, como diria o existencialista cristão Gabriel Marcel. Os caracteres distintivos da pessoa jamais podem ser dissociados dela a não ser pela ação do tempo (envelhecimento), através de doenças ou mesmo da morte. Esses elementos citados há pouco, atualmente parecem ser os únicos capazes de fazer com que o homem e a mulher de hoje se dêem conta dos padrões alienantes que adotam irrefletidamente fazendo-os transparecer em seus corpos algo que na realidade não são.

A ação do tempo, incluindo certeza da morte e as possíveis doenças, são hoje um monstro a ser enfrentado com todas as armas. A medicina trata do indivíduo como um "objeto de cuidados" visando manter a todo custo sua saúde. Cremes e outros cosméticos, como os fabricados pela famosa indústria francesa Garnier, ou então pela Avon, são espalhados profusamente no mercado a fim de auxiliar no combate às manchas e rugas com que o tempo costuma marcar os seres humanos. A busca por cirurgiões plásticos, ou mesmo um outro exemplo bem simples e comum em todas as classes sociais: a tintura para cabelos, a fim de esconder ou ao menos disfarçar a ação do tempo, também servem como indicadores da busca desesperada (ou ás vezes até natural) por formas de modificar ou retardar o processo comum de envelhecimento e morte próprio dos seres humanos.

O homem contemporâneo parece esquecer-se das limitações de sua natureza, ou se não esqueceu ao menos procura tentar fazê-lo. A morte é na opinião do mestre da moral ocidental, Santo Afonso Maria de Ligório, uma seta capaz de orientar o viver humano de forma eficaz, proveitosa e feliz, a ponto de que o mesmo autor, tomando um velho adágio da tradição eclesiástica, afirmou que "quem vive bem, morre bem". A consciência da finitude humana é uma força capaz de orientar sua vida de forma ponderada e concreta, jamais alienada. S. Afonso indica essa alienação "no homem que vive como se não devesse morrer". (LIGÓRIO, 2002, p. 12).

Observando esse contexto ideológico em que vivemos, mormente em relação ao corpo humano, poderíamos, na expressão de Heidegger, considerar os homens e mulheres que absorvem a idéia de que devem moldar seus corpos de acordo com as propostas do modelo 
capitalista internacional, como seres inautênticos. Nesse contexto alienado e alienante se interpõe um problema moral: nos prendemos com ávido interesse à nudez que apresenta corpos perfeito no cinema, nas exposições, nas revistas e em todos os demais meios de comunicação, porém, fazemos pouco ou nenhum caso de outra nudez, menos artística e mais escandalosa; e esta não é outra senão a nudez presente em favelas, casas ou locais de prostituição, cortiços, locais onde se encontram moradores de rua, etc.

Anteriormente dissemos que a filosofia deve partir do concreto para proporcionar uma discussão sempre mais próxima da verdade, sendo assim, somos chamados a observar uma realidade alarmante para os "seres inautênticos" em que muitos seres homens e mulheres vem se transformando: a morte do corpo. A questão da morte do corpo vem nos interpelar numa sociedade que o idolatra, que propõe a saúde como uma condição essencial para distinguir o que é considerado realmente humano, mas que, no entanto, é capaz de matar ou deixar morrer esse mesmo corpo. Tratando desse assunto não falamos, é claro, de toda a sociedade considerada como um monolito, inclusive é louvável a luta que muitos movimentos e grupos têm realizado em favor do resgate da verdadeira dignidade humana. A sociedade que abordamos no presente estudo não é outra senão a que estamos inseridos e, portanto, é algo concreto que serve de base à nossa reflexão filosófica, sobretudo, naquilo que concerne à formulação social das aparências (fetiches, ídolos, imagens idealizadas); ao universo da indústria cultural que influencia largamente os seres humanos de todas as idades e lugares (em maior ou maior ou menor escala); o sistema capitalista e a evolução e ampliação da sociedade tecnológica que vem redefinindo o tempo presente (modificando as relações humanas, as comunicações e até mesmo outras noções como tempo e espaço).

A ideologia, compreendida como um processo de mascaramento da realidade e apresentação idealizada de fetiches, vem se tornando um instrumento cada vez mais poderoso em poder de uma restrita elite de manipuladores de consciências que fazem com que verdadeiro seja tomado como falso e o falso como verdadeiro. Gradativamente os hábitos, conceitos, ações e ainda outros elementos próprios do ser humano vão se transformando, e em muitos casos chegam até mesmo a desfigurar-se.

A sofisticação da tecnologia de
persuasão, no último meio século,
modificou as velhas regras da
comunicação humana. À medida
em que a indústria da publici-
dade erelações públicas tornava-
se cada vez mais hábil em
controlar a opinião pública, as
posturas, as crenças e os sistemas
de valores, foi tornando-se um
imperativo manter o segredo e
capacitar a população a reprimir
a consciência daquilo que os
manipuladores estão tramando
(KEY, 1993, p. 313 e 319).

Em nosso tempo a luta de forças pela vida e contra ela parece ser constante. Se a Escolástica destacou na maioria de seus autores a constante luta entre Bem e Mal, hoje a mesma luta ainda ocorre, porém, revestida com uma moderna roupagem que comporta um sentido simbólico muito expressivo: a luta pela vida de alguns (considerados mais belos, por exemplo) em detrimento de milhões (que se situam entre as classes menos favorecidas). 
Essa realidade não deixa de ter um amargo sabor xenofóbico.

Ao matar o corpo, a sociedade portadora do medo, em que vivemos, procura eliminar essa possibilidade concreta de luta pela vida (em especial pela vida das classes oprimidas). Na América Latina, de modo especial, a objetificação do corpo é percebida no caso da mulher camponesa e proletária que vai sendo submetida ao uroxídio; é percebida na juventude e também nos anciãos, que segundo Dussel, são "sepultados vivos nos asilos pela sociedade de consumo". Com isso emerge também a questão bipolar da repressão sexual e da erotização da sociedade, que são frutos de injustiças políticas aliadas à manipulação das massas, visando a "massificação" da sociedade, como bem demonstrou Adorno em seus estudos. "A injustiça política é fratricídio, a morte do irmão: da nação irmã, do irmão classe, do outro como irmão próximo. A injustiça ou perversão no nível erótico, hoje, é o uroxídio (morte da mulher numa sociedade onde reina a ideologia machista, masculinista, falocrática como veremos). A erótica descreve a relação homem-mulher". (DUSSEL, 1980, p. 85)

Um outro jogo de forças no campo da corporeidade se encontra nos discursos religiosos, que certamente desempenham uma influência muito acentuada no comportamento das pessoas. Mesmo que nem todos os preceitos religiosos, como o caso da dignidade humana, sejam tomados em toda sua amplitude, sabemos que ainda assim exercem uma certa autoridade sobre as consciências. No caso específico da sexualidade, que é uma das mais elevadas expressões da corporei-dade humana, os ditames da religião são fundamentais para a compreensão do comportamento humano e de sua sexualidade.
Costuma-se enfatizar os aspectos conservadores e reacionários da religião (no caso, a cristã) face à sexualidade: bulas e encíclicas papais proibindo os anticoncepcionais, condenando o aborto, adultério, o homossexualismo, o divórcio; seitas protestantes, como a pentecostal, bradando que é chegado o fim do mundo porque os homens reconstruíram Sodoma e Gomorra; a severa austeridade do vestuário protestante e o obsessivo controle do corpo de crianças e adolescentes; a atribuição dos males e doenças ao gosto pelo prazer carnal, na fala inflamada dos pregadores.

Nesse contexto, as relações na sociedade se modificam ou são largamente influenciadas pelas questões que acabamos de expor, e desse modo objetificam o corpo através de uma visão por vezes "funcionalista" da sexualidade. Assim, homens e mulheres até mesmo em suas relações econômicas de produção, acabam criando objetos (no caso, os produtos), que por sua vez se lançam nas relações sócio-políticas como objeto em torno dos quais a vida se organiza em todos os seus encontros e desencontros. A partir disso surge a divisão social, provocadora dos mais diversos tipos de conflitos. Juntamente com os produtos, ou objetos, também produzimos símbolos que irão selar esta situação. Sendo assim, a idéia de necessidade, deve ser compreendida dentro desse contexto e em estreita ligação com a questão do consumo, que visa satisfazer às necessidades das pessoas conforme estas se apresentam. Ao final desse processo constatamos que o consumo acaba servindo de eficaz instrumento na acumulação do capital, através da qual é gerada e concebida uma sociedade de riquezas e abundância (no sentido mais abrangente dos termos), porém, o 
único problema é o resultado final de tudo isso: será que todos os que geram essas riquezas e abundâncias participam delas? Será que ao menos metade deles tem participação nisso? Parece-nos que para ambas as perguntas é praticamente impossível responder afirmativamente.

Dentro de um mundo que quer produzir e apoiar-se sobre aparências, a transformação do corpo em objeto é algo imprescindível. Outrora os homens se davam como mercadorias em troca do salário que o grupo capitalista lhes oferecia. Hoje na sociedade humana o que se pretende fazer é criar um processo destruidor do sentido real do corpo, que é então reduzido a um simples objeto que consome e é consumido. Aqui está o ponto crucial da questão da corporeidade humana, e se até agora afirmamos que uma reflexão filosófica pode contribuir muito no esclarecimento destas questões, a partir de agora não é possível prosseguir em nosso estudo sem um aprofundamento realmente filosófico.

Até agora o caminho reflexivo que percorremos procurou tratar da redução do corpo a objeto, partindo de composições diversas sobre o assunto, chegando à sua realidade concreta (e plenamente humana) que, nesse contexto invertido axiológicamente, em que nos encontramos precipita o corpo numa situação ambígua de valorização/ desvalorização, vida/morte. Para obter respostas condizentes às exigências da questão da corporeidade o caminho que a filosofia nos sugere não é o mais curto, porém, pode ser considerado entre os mais seguros. Esse caminho sempre parte do concreto para o abstrato e depois retorna ao concreto tentando superálo, e assim, esse processo não têm fim e sempre vai procurar oferecer respostas capazes de propor uma alternativa diferenciada para a superação do problema da corporeidade, que abarca uma série de outros problemas como os da identidade e dignidade humanas, por exemplo.

\section{Corpo e Cultura}

As modificações a que o corpo vem sendo submetido são fruto da influência exercida pela indústria cultural sobre as pessoas. Tal influência e mesmo as regras que são impostas à sociedade acabam atendendo aos interesses do modelo capitalista internacional, porém, cabe nos perguntarmos se as classes populares não influenciam também as classes dominantes. Seria isso possível?

A análise dessa questão, caso ofereça uma resposta positiva ou negativa, corre o risco de minimizar diversos outros elementos que podemos encontrar nesse contexto, por isso é bom antes de qualquer coisa, ponderar bem acerca da complexidade da situação.

O jornal Folha de São Paulo do dia 7 de agosto de 2006 noticiou a popularização dos penteados dreadlocks entre jovens da elite paulistana. Segundo a notícia, embora entre a elite paulistana tais penteados tenham aumentado consideravelmente, isso não é privilégio somente deles, mas uma tendência muito difundida entre jovens de todas as origens. Até a pouco, o chamado "visual rasta" era uma característica reconhecida em jovens das periferias, porém, atualmente a tendência se ampliou e chegou a salões paulistanos como os que se situam nos Jardins e em Higienópolis, o que demonstra o fato de que cada dia mais os penteados rastafári ganham espaço entre famílias abastadas. Junto com a nova 
tendência também chegaram as polêmicas familiares quanto à aceitação desses novos penteados.

Sendo um estilo diferenciado de penteado, os dreadlocks parecem ir se expandindo dia a dia, mesmo que seus usuários saibam que caso um dia queiram ter seu cabelo como antes, terão de raspar suas cabeças. Muitos dos adeptos vêem a origem do "visual rasta" nos ideais da chamada "religião de Bob Marley". A notícia apresentou inclusive a fala de uma jovem que afirmou identificar-se muito com essa religião, pois é vegetariana, não admite maus tratos quanto ao meio ambiente e não usa jeans, nem come nada que venha do McDonald's pelo fato de fazerem parte "do mundo do capitalismo".

Muita gente vê nessa valorização do visual rastafári um avanço quanto ao reconhecimento de outras culturas. No meio artístico brasileiro figuras como Adriane Galisteu, Ricardo Mansur, Gilberto Gil e Toni Garrido aderiam à moda, promovendo-a através disso.

Subvertendo a ordem caucasóide (etnia de origem européia), eles estão utilizando, com orgulho e beleza, elementos de afirmação da cultura negra "Pela arte e pela estética, estão enlouquecendo as famílias brancas por mudar suas características, levando para casa um choque cultural que faz as pessoas encararem e engolirem ofim da diferença". (BRITO, 2006, p. 6).

A moda rastafári vai crescendo através de um estilo diferente caracterizado por um cabelo com nós ou torcido que pode ser ajeitado de formas diversas: deixar o cabelo sem lavar, separando várias mechas e torcendo-as acrescentando ingredientes como a maionese, mel, pasta de dente, chiclete, areia, etc. Há quem prefira utilizar a cera de abelha. Por detrás desse estilo está a origem de tais práticas. Há registros que relatam o uso de dreads desde 1800 a. C na Etiópia, porém, seu uso espalhou-se por alguns lugares chegando à Jamaica e popularizandose com Bob Marley. Os ritmos musicais e costumes dessa cultura rastafári versam em geral acerca da "igualdade de direito, justiça social, consciência de sua história e valorização das raízes africanas, além da determinação em se tornar agente do próprio destino". O movimento rastafári tal como é conhecido hoje, teve suas origens na década de 30 , estruturando-se como um grupo religioso "quando Ras (significa duque ou chefe) Tafari Makonnen foi proclamado imperador adotando (...) títulos pomposos como "Rei dos Reis" e "Leão Conquistador da tribo de Judá". Segundo as profecias, o novo rei seria o messias que libertaria os negros do mundo inteiro. A partir daí, a história de Ras Tafari e da Etiópia, única terra africana a permanecer livre do jugo europeu, passaram a inspirar os rastas na Jamaica". (BRITO, 2006, p. 6).

Retornando à nossa problemática inicial, após expor a interessante influência que uma cultura "eurocêntrica", segundo as afirmações de Enrique Dussel, como é caso da nossa cultura latino americana, que vem sofrendo por parte de uma outra cultura que aos poucos vai conquistando seu espaço. Nesse ínterim, a questão do corpo está novamente em evidência e nesse caso cabe-nos analisar o porquê dessas mudanças. Que finalidade possuem? Simbólica e concreta-mente o que querem nos dizer os jovens que estão adotando o "visual rasta"?

Estas são questões que requerem respostas mais complexas 
do que pode parecer. A linguagem do corpo nesse caso pode representar uma ruptura com o mundo capitalista que nos cerca; pode representar a adoção e o empenho em lutar pelos ideais propostos por Bob Marley e outros "líderes" rasta; pode indicar um ideal de vida comprometido com cultura africana que influenciou de forma marcante na formação do povo brasileiro; ou por fim, pode também indicar que com a popularização dessa cultura, nenhum dos sentidos aludidos acima são levados tão a sério assim, e que, se essas expressões culturais tem se difundido é porque também elas já foram coisificadas pelo modelo capitalista em que vivemos! Ou seja, foram reduzidas ao mero $\mathrm{e}$ passageiro modismo que afeta praticamente todos os setores da sociedade, sem isentar nenhum, inclusive a religião; um exemplo disso foi a onda de padres cantores e a popularização dos chamados showsmissa difundidos no Brasil de 1997 em diante.

Muitos dos jovens que aderiram ao visual rasta mal sabem da ideologia que o sustenta, da história que está por detrás dele e muitos outros elementos que desconhecem. Não seria essa mais uma onda que hoje canoniza um costume, uma prática, um estilo, e amanhã o troca por outro que venda mais, que seja mais atraente? Muito provavelmente nossa resposta poderá ser positiva.

Uma série de outros costumes ainda podem ser elencadas, como o uso de piercings e tatuagens. Tal difusão dá-se pelo conhecido processo psicológico em que o ser humano tem de buscar seu grupo, seu círculo de relações, de forma que muitas vezes acaba se adequando ao grupo. Dificilmente um jovem que faz parte de um grupo de amigos onde todos usam tatuagens, não será influenciado a também usá-las. E o mesmo acontece em relação a outros elementos como o hábito de beber ou fumar. Nesse contexto, o corpo é que vai sofrendo mudanças ou sendo marcado conforme a orientação de cada grupo, cada vez mais percebemos o quanto é complexa a questão da corporeidade humana.

Os antropólogos e sociólogos debruçam-se sobre os usos sociais do corpo e tentaram descrevê-lo como um dos produtos culturais próprios a cada sociedade, até mesmo como um dos principais pontos de impacto da aculturação. Os semiólogos descreveram o corpo como um sinal. Os psicanalistas sublinharam o desvio que subsiste entre os significantes do desejo e as atualizações pulsionais sintomáticas e eróticas. Enfim, os filósofos, particularmente os fenomenólogos, buscaram esclarecer, mostrando a presença, em todo ser humano, de um corpo-objetorgânico (Korper) e ao mesmo tempo de um corposujeitointencional (Leib). (MARZANO -PARISOLI, 2004, p. 9)

$\mathrm{Na}$ esteira de Gabriel Marcel, que afirmou: "eu sou meu corpo", também nós propomos essa visão total do ser humano como uma resposta eficaz e coerente (porém, não definitiva) aos apelos que a sociedade instrumentalizadora do corpo requer. Ao tentar estabelecer uma "ética do corpo" não temos a pretensão de firmar pressupostos imutáveis, partindo de respostas prontas ou soluções e modos de agir pré-estabelecidos e muito seguros. Ao contrário, pretendemos conhecer as causas do problema tal como se apresenta atualmente e oferecer-lhe uma resposta condizente à medida do possível. "Uma das hipóteses 
propostas é que a relação corpopessoa pode ser qualificada como uma relação de posse ontológica: uma relação interna e particular que significa que, entre as condições que fazem com que eu seja a pessoa que sou, verifica-se que sou constituído deste corpo e não de um outro". (MARZANO-PARISOLI, 2004, p. 13). Esse conhecimento em relação ao nosso próprio corpo é algo que pertence a cada indivíduo, pois jamais os outros poderão possuir esse mesmo conhecimento da nossa sensibilidade corporal. Ao nos depararmos com essa realidade temos diante de nós outras questões candentes: o direito de dispor do corpo e o reconhecimento de sua inviolabilidade.

Embora sendo uma coisa, o corpo é uma coisa que me pertence e que me coloca em contato com o mundo externo. "O que há de único num corpo humano é, de fato, que ele é encarnação de uma pessoa: ele é o lugar onde nascem e se manifestam nossos desejos, nossas sensações e nossas emoções; ele é o meio pelo qual podemos demonstrar que tipo de seres morais nós somos". (Ibid. p. 14).

Ao mesmo tempo em que estamos tão próximos de nosso corpo, nos distanciamos dele. Há no ser humano outros elementos que ultrapassam o corpo, porém, como seres encarnados, nada conhecemos sem nosso corpo. Simultaneamente possuímos e somos nosso corpo.

\section{Abstract}

This work presents a study of the relationships between body, culture and society, disclosing the body issue as a guide to human action in the world. The society that is characterized by capitalist circumstances applies a body annihilation, transforming it in a source of market, media, esthetics and health exploitation. The symbolic and cultural productions generated in this context carry a alienation feeling and the destruction of body as a alterity and profound communication relationship.

Key Words: body, society, cultura and ethics.

\section{Referências}

BADIOU, Alain. O outro existe? In: Ética - um ensaio sobre a consciência do mal. Paris: Relume Dumara, 1993.

BADOU. Les corps Défendu. Quand la médecine dépas-se les bornes. Paris: Lattés, 1994.

BALMARY, M. Le sacrifice interdit. Paris: Grasset, 1986.

BARTHES, R., Systeme de la mode. Paris: Seuil, 1967.

BERNARD, M., Le corps. Paris: Seuil, 1995.

BOLDA, Márcio S. Rosto e alteridade: pressupostos da ética comunitária. São Paulo: Paulus, 1995.

BRIT0, Denise. Debaixo dos caracóis dos seus cabelos. Folha de São Paulo, São Paulo, 7 agosto 2006. Folhateen, p. 6.

BROHM, J.M., Constructions du corps: quel corps? In: GARNIER, C. (Ed.). Les corps rassemblé. Ottawa, Ed. D’Agence d’Arc, 1991.

BRUAIRE, C. Philosophie du corps. Nova lorque: Balantine, 1984.

CHAUÍ, Marilena. Repressão sexual:essa nossa (des)conhecida. São Paulo: Brasiliense, 1984.

O que é ideologia? São Paulo:

Brasiliense, 1989. (Col. Primeiros Passos).

CHIRPAZ, F. Le corps. Paris: Puf, 1977.

DE BEAUVOIR, S. Le deuxiéme sexe. Paris: Gallimard, 1949

DUSSEL, Enrique. Filosofia da Libertação: na América Latina. São Paulo: Loyola, 1980. p. 85.

GOLDSCHMIDT, P. Pornography and Democratization. Boulder: Westview Press, 1988.

HEINEMANN, Uta Ranke. Eunucos pelo reino de Deus:mulheres, sexualidade e a Igreja Católica. 
Rio de Janeiro: Rosa dos Tempos, 1996.

IGARELLO, G. Le corps redressé. Paris: Delarge, 1978.

KINSEY,A.C., ET AL. Sexual behaviour in the human male. Filadelfia: Saunders, 1948 Sexual Behaviour in the human female. Filadelfia: Saunders, 1953.

LACROIX, X. Le corps de chair.Paris: le Cerf, 1992.

LIGÓRIO, Santo Afonso de. Preparação para a morte. Aparecida: edição PDF de Fl. Castro, 2002, p. 12.

MARZANO-PARISOLI, R. M., Pensar o Corpo. Petrópolis: Vozes, 2004, p. 9, 13 e 14.

MERLEAU-PONTY, Maurice. Signes. Paris: Gallimard, 1960.

NUNES, Etelvina. $O$ outro e o rosto: problemas da alteridade em Emmanuel Lévinas. Braga: Publicações da Faculdade de Filosofia da UCP, 1993.

OVERBERG, K. R., Consciência em Conflito. São Paulo. Paulus, 1999.

PAIVA, Márcio. Subjetividade e infinito:o declínio do Cogito e a descoberta da alteridade. In: Revista Síntese, n.88, p. 213-230, maio/ago., 2000.

PARKER, R. A construção da solidariedade:aids, sexualidade e política no Brasil. Rio de Janeiro: Relumé-Dumará/ ABIA/ IMS-UERJ, 1994.
Na contramão da Aids: sexualidade, intervenção, política. São Paulo: Editora 34/ ABIA, 2000.

PEgORAR0, Olinto A. Ética e Boética: da subsistência à existência. Petrópolis:Vozes, 2002.

PIVATTO, Pergentino S. Ética da alteridade. In: Corrente fundamentais da ética contemporânea. Petrópolis: Vozes, 2000.

REVISTA DE HUMANIDADES. Fortaleza: CCH/ NUPECH, jan.jjul. 2002 - Semestral.

ROGERS, M.F., Barbie Culture. Londres: Sage, 1999

SELLA, Adriano. Ética da justiça. São Paulo: Paulus, 2003.

SULLIVAN, B. The Politics of Sex. Cambridge: Cambridge Univ. Press, 1997.

SYNOTT, A. The Body Social:Simbolism, Self and Society. Londres: Sage publ., 1993

TRASFERETTI, José. "Teologia moral na pósmodernidade": o difícil dilema do agir moral. In: TRASFERETTI, José; GONÇALVES, Paulo Sérgio Lopes (Orgs.). Teologia na pós-modernidade: abordagens epistemológica, sistemática e teórico-prática. São Paulo: Paulinas, 2003.

Ética e Responsabilidade Social. Campinas: Alínea, 2006.

VESALE. La Fabrique du corps humain. Paris: Inserm, 1987.
Data do recebimento: 03/05/2008

Data do aceite: 15/05/2008 